\title{
Synthesis, Characterization and Photocatalytic Efficiency of ZnO/MWCNT Nanocomposites Prepared Under Different Solvent Conditions
}

\author{
E. Bartfai ${ }^{1}$, K. Nemeth ${ }^{1}$, B. El Mrabate ${ }^{2}$, M. Udayakumar ${ }^{2}$, K. Hernadi ${ }^{1}$, and Z. Nemeth ${ }^{1,2, *}$ \\ ${ }^{1}$ Department of Applied and Environmental Chemistry, University of Szeged, Rerrich Béla tér 1, Szeged, H-6720, Hungary \\ ${ }^{2}$ Institute of Chemistry, University of Miskolc, Miskolc-Egyetemváros, Miskolc, H-3515, Hungary
}

\begin{abstract}
Here we report the application of zinc oxide $(\mathrm{ZnO})$ coated multi-walled carbon nanotube (MWCNT) composites in the photocatalytic decomposition of acetaldehyde (AA). Zinc oxide nanoparticles were successfully coated on the multi-walled carbon nanotube via impregnation process using zinc acetate $\left(\mathrm{Zn}\left(\mathrm{CH}_{3} \mathrm{COO}\right)_{2} \times 2 \mathrm{H}_{2} \mathrm{O}\right)$ as precursor and sodium dodecyl sulfate (SDS) treated multiwalled carbon nanotube as raw material under different solvent conditions. The applied solvents during preparation were ethanol $(\mathrm{EtOH})$ and water $\left(\mathrm{H}_{2} \mathrm{O}\right)$. As-prepared materials were characterized by thermal analysis (TG), X-ray diffraction (XRD), specific surface area measurement (BET) and transmission electron microscopy (TEM) techniques. Photocatalytic efficiencies of as-prepared composites were investigated in a stationary reactor equipped with UV lamp. Decomposition of acetaldehyde was followed by using gas chromatography (GC). Observations revealed that using impregnation method and different solvents the preparation of ZnO/MWCNT nanocomposites can be controlled easily. The highest degradation rate was achieved with the nanocomposite was synthetized using ethanol as solvent. The photocatalytic experiments revealed that the composite has higher photocatalytic activity than that of both the zinc oxide nanoparticles and the mechanical mixture of multi-walled carbon nanotube and zinc oxide.
\end{abstract}

Keywords: Nanocomposite, Zinc Oxide, Transmission Electron Microscopy, Photocatalysis, Gas Chromatography.

\section{INTRODUCTION}

Nowadays, scientists are inspired to find alternative procedures for solving the problems with the water contaminants and pollutants predicted. One of these trends is the development of photoactive carbon based nanocomposites, in which numerous promising semiconductors have been tested. ${ }^{1}$

Carbon nanotubes (CNTs) have exceptional properties thereby resulting in many potential applications. ${ }^{2,3}$ Due to their high specific surface area and adsorption capability multi-walled carbon nanotube (MWCNT) have been increasingly used in environmental applications. ${ }^{4}$ As a support for semiconductor with photocatalytic properties carbon nanotubes has certain advantages because it is inert in the most reaction conditions, they can provide high dispersion of semiconductor photocatalysts and creates many active sites for the photocatalytic decomposition. ${ }^{5}$

\footnotetext{
*Author to whom correspondence should be addressed.
}

As it reported earlier MWCNT can conduct electrons and also could have high adsorption capacity for certain organic substrates. ${ }^{6}$

The major drawback in photocatalysis is to have a chance of recombination of charges avoiding photodegradation. This electron-hole recombination can be prevented by making a composite MWCNT material with other semiconductor nanoparticles or metal oxides. MWCNT captured electrons due to its high charge conducting ability that ultimately gives less chance to electrons for recombining with holes. So, MWCNT can be called as photo-generated electron acceptor that enhances interfacial electron transfer process, whereas the semiconductors are good electron donors under irradiation. ${ }^{7-10}$ Applying different preparation methods, many types of semiconductor metal oxides, such as $\mathrm{TiO}_{2},{ }^{11,12} \mathrm{SnO}_{2},{ }^{13} \mathrm{Cu}_{2} \mathrm{O},{ }^{14} \mathrm{CeO}_{2}{ }^{15}$ and $\mathrm{ZnO}^{16-18}$ have been coated on MWCNT in earlier studies.

As a promising semiconductor material with a wide band gap of $3.37 \mathrm{eV}$ and a large exciton binding energy 
$(60 \mathrm{meV})$ at room temperature, ${ }^{19} \mathrm{ZnO}$ has received widespread attention as optoelectronic materials because of its excellent performance in electronics, optics, and photonics systems. ${ }^{20}$ It also has a potential application in photocatalytic degradation of organic compounds under UV irradiation. ${ }^{21,22}$ Furthermore, $\mathrm{ZnO}$ nanoparticles have several advantages for photocatalytic reactions, such as high optical activity, stability and high sensitivity for UV-vis light. $^{23}$

Up to know, various methods, such as chemical vapour deposition (CVD), plasma assisted sputter and vacuum infiltration, have been carried out to modify the surface of MWCNT with $\mathrm{ZnO}$ nanoparticles. ${ }^{24-26}$ Koh et al. also reported the coating of $\mathrm{ZnO}$ nanorods on MWCNT using hydrothermal synthesis. ${ }^{27}$ CNTs decorated with ZnO nanoparticles were synthesized by Chen et al. through oxidization, amination and modification of MWCNT with $\mathrm{H}_{2} \mathrm{SO}_{4}, \mathrm{NH}_{3}$ and $\mathrm{HNO}_{3} \cdot{ }^{28} \mathrm{Li}$ et al. synthesized ZnO-MWCNT-reduced graphene oxide (RGO) ternary nanocomposites via a simple one-pot hydrothermal process using graphene oxide (GO)-dispersed MWCNT and zinc nitrate as raw materials. ${ }^{29}$

Since CNTs are chemically inert surface modification of carbon nanotubes are required to promote the attachment of nanoparticles. Covalent modification of the nanotube sidewalls could change the electronic properties of the nanotubes. Noncovalent modification of MWCNT could be a promising alternative to prepare MWCNT based nanocomposites. ${ }^{30}$ In order to favor the dispersion of CNTs in water the widely and most used approach is the adsorption of surfactants onto the nanotube sidewalls. Their main advantages are their cheapness, their ready commercial disposability and simplicity of use. These small molecules have typically a hydrophobic tail and a hydrophilic head group, the former is intended to favor adsorption onto the hydrophobic nanotube walls and the latter to promote affinity with the aqueous bulk solvent. ${ }^{31}$ As Jiang et al. reported sodium dodecyl sulfate (SDS) can noncovalently modify the MWCNT surface through hydrophobic interaction. ${ }^{32}$

In hybrid systems, control of the particle size and morphology by a facile and low cost method is essential to their applications in photocatalytic reactions. The aim of this work was to present a simple route to produce $\mathrm{ZnO}$ nanoparticles on the surface of modified MWCNT.

Procedures were developed to form coatings on the surface of MWCNT under solvent conditions applying impregnation method. The acetaldehyde (AA) decomposition reactions were used to test the photocatalytic efficiencies of ZnO-covered MWCNT nanocomposites.

\section{EXPERIMENTAL DETAILS}

\subsection{Materials}

As it was described in our earlier papers [33, 34] MWCNT was prepared by the catalytic chemical vapour deposition (CCVD) method in a rotary oven at $720{ }^{\circ} \mathrm{C}$ in nitrogen flow. ${ }^{35}$ Acetylene was used as carbon source and $\mathrm{Fe}, \mathrm{Co} / \mathrm{CaCO}_{3}$ as catalyst, and the total concentration metal was 5 wt $\%{ }^{36}$ The support material and the catalyst particles were removed with stirring the product in $10 \%$ hydrochloric acid for $1 \mathrm{~h}$, and then it was washed with diluted $\mathrm{HCl}$ and subsequently with distilled water until neutral $\mathrm{pH}$ was achieved. The average diameter of the MWCNT was 20-60 nm, while average lengths were about few hundred nanometers to few micrometers. ${ }^{29,30}$ The specific surface area of the MWCNT was $182.1 \mathrm{~m}^{2} / \mathrm{g}$. The main features of MWCNT Raman spectra are the D, $\mathrm{G}$ and $\mathrm{G}^{\prime}$ peaks. The purity of the carbon phase can be easily determined by the rations of these three peaks, and the metal content was previously regarded with a quantitative ICP-MS analysis. ${ }^{37}$ This analysis and peak intensity ratios in case of MWCNT indicate good quality and highly graphitic nature.

For composite fabrication all chemical reagents, such as zinc acetate $\left(\mathrm{Zn}\left(\mathrm{CH}_{3} \mathrm{COO}\right)_{2} \times 2 \mathrm{H}_{2} \mathrm{O}\right)$ and sodiumdodecyl-sulphate (SDS) purchased from Sigma-Aldrich, were analytical grade and used without further purification. Distilled water and absolute ethanol (EtOH-VWR Prolabo) were used as the solvents of the precursor compound.

\subsection{Modification of MWCNT and}

\section{Nanocomposite Preparation}

The chemical adsorption of SDS molecules on the surface of the MWCNT induces electrostatic repulsion between polar heads that expose in the aqueous solution thus preventing CNTs aggregation and inducing the formation of stable black suspensions. Noncovalent functionalization of MWCNT is necessary, therefore pristine nanotubes were dispersed in $2 \mathrm{wt} \%$ dilute SDS aqueous solution $^{31}$ to modify MWCNT surface by ultrasonication. The $\mathrm{ZnO} / \mathrm{MWCNT}$ composites were prepared by a simple impregnation method. Surface treated MWCNT was applied as raw material and $\mathrm{Zn}\left(\mathrm{CH}_{3} \mathrm{COO}\right)_{2} \times 2 \mathrm{H}_{2} \mathrm{O}$ as precursor compound. MWCNT contents were fixed at $10 \mathrm{wt} \%$ of the total $\mathrm{ZnO} / \mathrm{MWCNT}$ composites calculated to the final crystallized product after annealing. Initially, $0.1 \mathrm{~g}$ SDS modified MWCNT was dispersed in $50 \mathrm{~mL}$ water and $\mathrm{EtOH}$ via ultrasonication for $15 \mathrm{~min}$. During this time the calculated amount of precursors $(2.45 \mathrm{~g})$ was dissolved in another $50 \mathrm{~mL}$ of water and $\mathrm{EtOH}$. To completely dissolve the precursors, the solution was stirred vigorously using a magnetic stirrer for $10 \mathrm{~min}$ at $300 \mathrm{rpm}$. Finally, the solution of the precursor was added drop by drop $(\sim 2 \mathrm{~mL} / \mathrm{min})$ to the MWCNT suspension under continuous stirring. Then, the mixture was heated to $40{ }^{\circ} \mathrm{C}$ to evaporate EtOH and $70{ }^{\circ} \mathrm{C}$ to evaporate $\mathrm{H}_{2} \mathrm{O}$ on a hot plate. Composite powder was further dried at $70{ }^{\circ} \mathrm{C}$ in air for $12 \mathrm{~h}$. Finally, the as-prepared nanomaterials were annealed in a static furnace in air with a heating rate of $5{ }^{\circ} \mathrm{C} / \mathrm{min}$ for $3 \mathrm{~h}$ at $300{ }^{\circ} \mathrm{C}$ to obtain crystalline $\mathrm{ZnO}$. The reference 

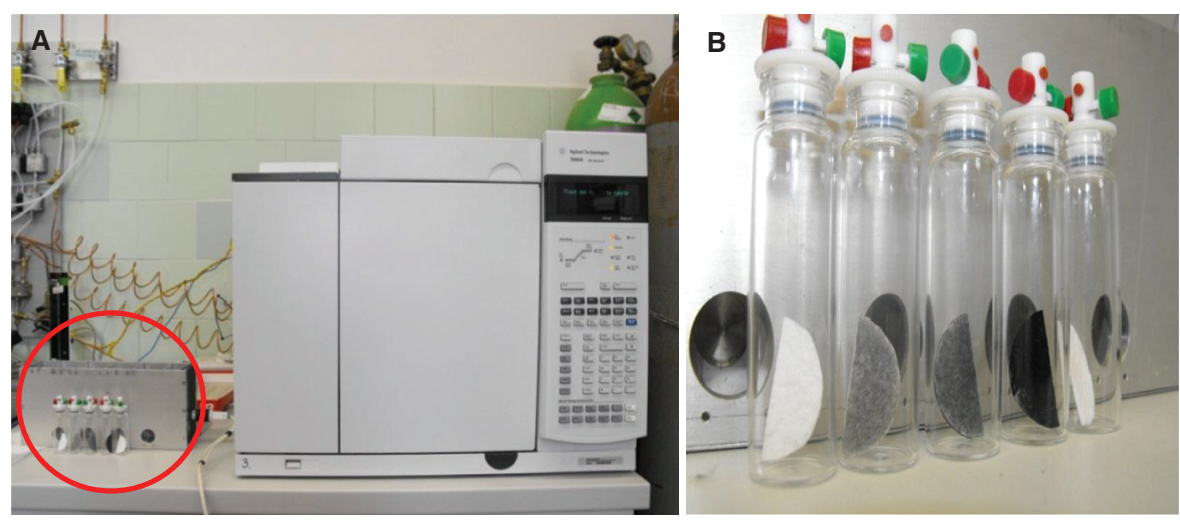

Figure 1. UV photoreactor (left corner-A) with GC (A) and glass vials with $\mathrm{ZnO} / \mathrm{MWCNT}$ nanocomposites, pristine $\mathrm{ZnO}$, alumina paper and MWCNT (B).

materials of $\mathrm{ZnO}$ for comparative examinations were prepared exactly in the same way as the composites without the presence of MWCNT.

\subsection{Sample Characterization}

The formation of inorganic nanoparticles on the surface of MWCNT was verified by transmission electron microscopy (TEM, Philips CM10). For TEM investigations, a small amount of the sample was sonicated in $1.25 \mathrm{~mL}$ of distilled water. Then, a few drops of this suspension were dribbled onto the surface of the grid (LC200$\mathrm{Cu}$ TEM grid covered with lacey carbon film-Electron Microscopy Sciences-USA). The crystalline structure of the as-prepared membrane was determined by powder $\mathrm{X}$-ray diffraction method (Rigaku Miniflex II Diffractometer) utilizing characteristic X-ray $(\mathrm{CuK} \alpha(\lambda=1.5405 \AA))$ radiation. Scanning was carried out over a $2 \theta$ range of $10-80^{\circ}$ with a step size of $0.0167^{\circ}$. The specific surface areas of the samples were determined by the adsorption of nitrogen at $77 \mathrm{~K}$ according to the method of BrunauerEmett-Teller. ${ }^{38}$ After the samples were pre-treated at $300{ }^{\circ} \mathrm{C}$ for $15 \mathrm{~min}$ in helium atmosphere $(50 \mathrm{~mL} / \mathrm{min})$, measurements were carried out by a single point BET instrument (BEL Japan Inc. BELCAT-A). Thermogravimetric analysis (NETZSCH STA 409 PC connected to a Pfeiffer QMS 200 mass spectrometer system) was performed in air (measurement range: $25-800{ }^{\circ} \mathrm{C}$, flow velocity: $40 \mathrm{~mL} / \mathrm{min}$, heating rate $10{ }^{\circ} \mathrm{C} / \mathrm{min}$ ) using $100 \mathrm{mg}$ sample.

\subsection{Determination of Photocatalytic Efficiency}

Photocatalytic experiments were carried out using the system which can be seen in Figure 1. The applied UV photoreactor (Fig. 1(A) — marked by red circle) was equipped with fluorescent lamp (Vilber-Lourmat T-6L UV-A, 6 W power, radiation maximum at $365 \mathrm{~nm}$ ). The added amounts of the photocatalysts were $0.5 \mathrm{~g} / \mathrm{L}$, and AA, a harmful chemical material, (Spektrum3D, 99.0\%) was used to characterize the photocatalytic activity of the specimen.
First, MWCNT composites were suspended in EtOH with a concentration of $0.5 \mathrm{mg} / \mathrm{mL}$. In the next step $100 \mathrm{~mL}$ portions of these $\mathrm{ZnO} / \mathrm{MWCNT}$ suspensions were deposited onto a high purity alumina based ceramic papers (COTRONICS Corporation-Ultra Temp 300) ${ }^{39}$ with a diameter of $47 \mathrm{~mm}$ by simple filtration, enhanced with vacuum suction. Every suspension was used within a few hours to avoid MWCNT aggregation, which could alter the final performance of the membranes. As a final step, the as-prepared MWCNT composite membranes were dried on $100{ }^{\circ} \mathrm{C}$ for 30 minutes in order to remove residual solvents. As-prepared alumina based ceramic membranes, with a load of $0.75 \mathrm{mg} / \mathrm{cm}^{2}$ (50 mg/membrane), were cut into half to fit into the sample vial easily and placed into glass vials equipped with opening and locker plastic head as can be seen in Figure 1(B). Glass vials were rinsed with $\mathrm{N}_{2}$ gas before starting the photocatalytic decomposition of AA. Then, vials were filled with saturated vapour of AA $\left(0,987\right.$ bar; $\left.20{ }^{\circ} \mathrm{C} ; 0.9 \mathrm{mM}\right)$ and wait until the adsorption equilibrium state ( $\sim 40 \mathrm{~min})$. Vials were placed into a stationary reactor and irradiated the specimen in AA atmosphere with a wavelength of $365 \mathrm{~nm}$ at room temperature for $120 \mathrm{~min}$. Changes in AA concentrations were followed with gas chromatograph (Agilent $6890 \mathrm{~N}$ ) using a HP-PLOT Q column, equipped with thermal conductivity (TC) and flame ionization (FI) detectors and Agilent 5975C VL MSD mass-spectrometer. The split ratio was 10:1 in all cases. Each nanocomposite sample was tested three times. As it was reported previously several types of intermediates can be generated during the decomposition of AA (e.g., formaldehyde, acetic acid), ${ }^{40}$ however, the main product was $\mathrm{CO}_{2}$. In this report the determination of $\mathrm{CO}_{2}$ by gas chromatography was performed.

\section{RESULTS AND DISCUSSION}

\subsection{Heat Treatment, Crystal Structure Analysis and} Surface Area Measurement

In order to identify the $\mathrm{ZnO}$ nanoparticles and also to transform the amorphous phase into crystalline phase, 


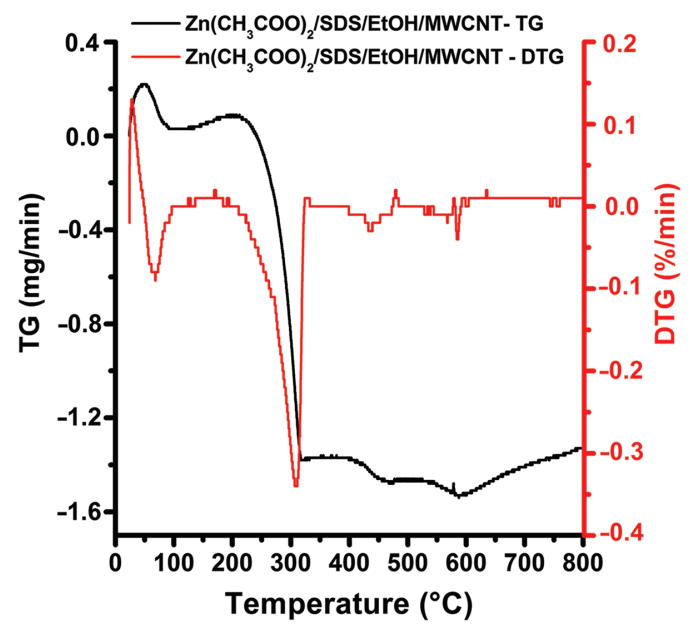

Figure 2. Thermal analysis of $\mathrm{Zn}\left(\mathrm{CH}_{3} \mathrm{COO}\right)_{2} \times 2 \mathrm{H}_{2} \mathrm{O} / \mathrm{SDS} /$ EtOH/MWCNT nanocomposite material.

the composite samples were heat treated. Before that the DTG gave us important information about the phase transformations which occurred because of the rise of the temperature (Fig. 2). The first thermal event was observed up to $100{ }^{\circ} \mathrm{C}$ with a $\sim 14.9 \%$ weight loss. This weight loss can be attributed to the thermal dehydration of zinc acetate dihydrate and more specifically to the loss of the two water molecules. By further increasing the temperature, the decomposition of anhydrous $\mathrm{Zn}\left(\mathrm{CH}_{3} \mathrm{COO}\right)_{2}$ into $\mathrm{ZnO}$ occurs at $\sim 250{ }^{\circ} \mathrm{C}$, and is completed at $\sim 300{ }^{\circ} \mathrm{C}$ with a $\sim 28.8 \%$ weight loss. Beyond this temperature, and up to $400{ }^{\circ} \mathrm{C}$, the formation of stable $\mathrm{ZnO}$ crystal takes place. Based on these results, we decided to carry out the calcination at $300{ }^{\circ} \mathrm{C}$ for $3 \mathrm{~h}$, since a stable $\mathrm{ZnO}$ phase is obtained. These observations are also in good agreement with previously reported result. ${ }^{41}$ Further thermal event can be noticed from $450{ }^{\circ} \mathrm{C}$ to $550{ }^{\circ} \mathrm{C}$ with a $\sim 4.8 \%$ weight loss, which belongs to the burning of SDS modified MWCNT.

The degree of crystallization of composite samples was investigated by XRD. The results of analysis are presented in Figure 3. The diffraction peak at $2 \theta=26.5^{\circ}$ can be identified as the 002 reflection of MWCNT. The other diffraction peaks in the range of $20^{\circ}<2 \theta<80^{\circ}$ correspond to the (100), (002), (101), (102), (110), (103), (200), (112), (201), (004) reflections of $\mathrm{ZnO}$. The average crystalline size of inorganic particles can also be estimated from X-ray diffractograms by the Scherrer equation: ${ }^{42}$

$$
D=(K \lambda) /(\beta \cos \theta)
$$

Where $D$ is the diameter (in nanometer) of the grain or the layer, $K$ is the shape factor (0.89), $\lambda$ is the X-ray wavelength of $\mathrm{Cu} \mathrm{K} \alpha(0.154 \mathrm{~nm}), \beta$ is the experimental fullwidth half maximum of the respective diffraction peak(s), and $\theta$ is the Bragg angle. Furthermore, from the analysis of the TEM pictures, the average particle sizes were also

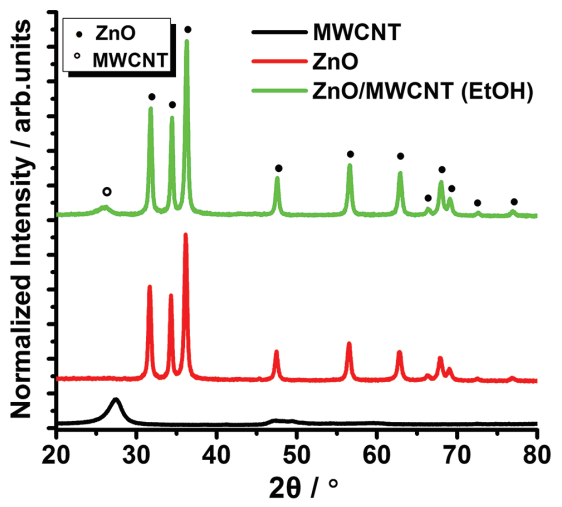

Figure 3. X-ray diffractograms of heat treated raw materials and $\mathrm{ZnO} / \mathrm{MWCNT}$ nanocomposite sample prepared in $\mathrm{EtOH}$.

calculated using iTEM software (Olympus Soft Imaging Solutions). The particle size distribution was determined by measuring the size of 100 particles in case of all samples. We took into consideration that the TEM images only show a $2 \mathrm{D}$ projection of the $3 \mathrm{D}$ particles, thus the observed particle size distribution is actually a distribution of the projected dimension of the particles. Particle size values obtained with the two different calculations showed good agreement. Table I shows the average particle diameters $\left(d_{\mathrm{av}}\right)$ in nanometers, calculated from TEM and XRD investigations. In case of pure MWCNT, TEM images were used only to determine the average diameter. As-prepared MWCNT-based filter materials were also characterized by $\mathrm{N}_{2}$ adsorption technique to measure their specific surface area. Table I shows the measured specific surface area values.

\subsection{TEM Analysis}

After the heat treatment MWCNT based composite samples were investigated by TEM technique. Figure 4 shows TEM micrographs at various magnifications of the prepared $\mathrm{ZnO} / \mathrm{MWCNT}$ nanocomposites. The fabrication of $\mathrm{ZnO} / \mathrm{MWCNT}$ composites using $\mathrm{Zn}\left(\mathrm{CH}_{3} \mathrm{COO}\right)_{2} \times 2 \mathrm{H}_{2} \mathrm{O}$ as precursor and SDS modified MWCNT was successful using both of solvents, although different composite structures were observed during TEM observations. Figures 4(A)-(B) shows representative electron micrographs obtained from the investigation of composite materials prepared in ethanol. TEM images revealed that the majority of MWCNT were covered by $\mathrm{ZnO}$ nanoparticles

Table I. Particle size and specific surface area of raw materials and MWCNT based composites.

\begin{tabular}{lcc}
\hline Sample name & $d_{\text {average }}(\mathrm{nm})$ & $\mathrm{BET}\left(\mathrm{m}^{2} / \mathrm{g}\right)$ \\
\hline MWCNT & $35.8(\mathrm{TEM})$ & 182.1 \\
$\mathrm{ZnO}$ & 15.1 (TEM and XRD) & 51.2 \\
$\mathrm{ZnO} / \mathrm{MWCNT} / \mathrm{EtOH}$ & 20.2 (TEM and XRD) & 64.3 \\
$\mathrm{ZnO} / \mathrm{MWCNT} / \mathrm{H}_{2} \mathrm{O}$ & 23.4 (TEM and XRD) & 61.8 \\
\hline
\end{tabular}



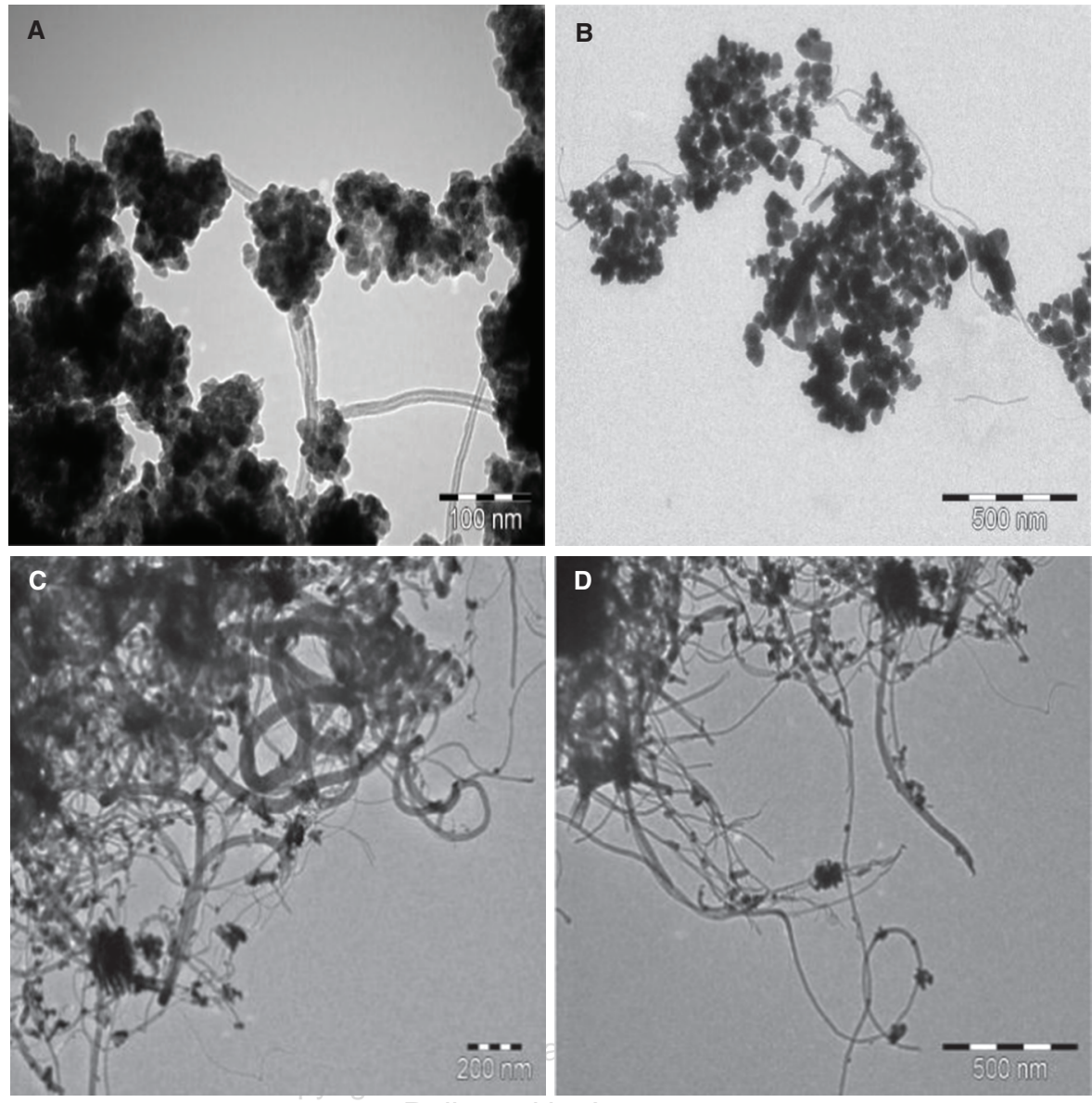

Figure 4. TEM images of $\mathrm{ZnO} / \mathrm{MWCNT}$ nanocomposites applying $\mathrm{EtOH}(\mathrm{A}, \mathrm{B})$ and water (C, D) as solvent.

and segregated particles could not be observed during analysis. Figures 4(C)-(D) present views of the nanocomposite sample prepared in water and these images clearly demonstrated that the surface of MWCNT was covered weakly with $\mathrm{ZnO}$ nanoparticles. Larger, segregated $\mathrm{ZnO}$ crystallites and uncovered MWCNT were also observed when water was used as solvent. Analysing as-prepared products it can be concluded that EtOH provide more uniform $\mathrm{ZnO} / \mathrm{MWCNT}$ nanocomposite samples. In previously published results, $\mathrm{ZnO}$ crystallites with different morphologies can be observed by using different solvents, such as water, ethanol and $n$-propanol. ${ }^{43}$ The surface tensions of these solvents are very different from each other, so the final composite morphology can be varied easily by changing the solvent.

\subsection{Photocatalytic Efficiency}

Before photocatalytic measurements, blank experiments were carried out to determine the decomposition of AA without any photocatalysts. The AA transformation was below 5\% during 120 min long irradiation. The adsorption capacities of laboratory-prepared nanocomposites were also measured in dark experiences. Results pointed out that nanocomposites produced via the utilization of $\mathrm{EtOH}$ solvent during the synthesis method resulted in higher adsorption ability. These materials adsorbed $10-15 \%$ of AA at applied concentration after 120 min. in dark, while nanocomposites produced in water solution adsorbed only $5-8 \%$ of AA. The estimated difference in adsorption capacities can not be connected to the specific surface areas, since these properties of the materials are very similar (see Table I). The difference probably due to some unclarified special surface property, resulted by the different solvents applied during synthesis methods. The adsorption capacity of pristine alumina ceramic paper was also investigated under dark conditions. Pure alumina membrane adsorbed only 1-3\% of AA (Fig. 5-brown curve).

The photocatalytic behaviors of the raw materials, the pure alumina ceramic paper, the simple mechanical mixture of MWCNT and $\mathrm{ZnO}$, and $\mathrm{ZnO} / \mathrm{MWCNT}$ composites were examined as shown in Figure 5. In case of $\mathrm{ZnO}+\mathrm{MWCNT}$ mechanical mixture the MWCNT content was $10 \mathrm{wt} \%$ also. Comparing the decomposition efficiency of the modified MWCNT, the pristine $\mathrm{ZnO}$, the mechanical mixture of MWCNT and $\mathrm{ZnO}$ with the as-prepared $\mathrm{ZnO} / \mathrm{MWCNT}$ nanocomposites it was found that $\mathrm{ZnO} / \mathrm{MWCNT}$ nanocomposites have comparatively higher photocatalytic activity as can be seen in Figure 5. 


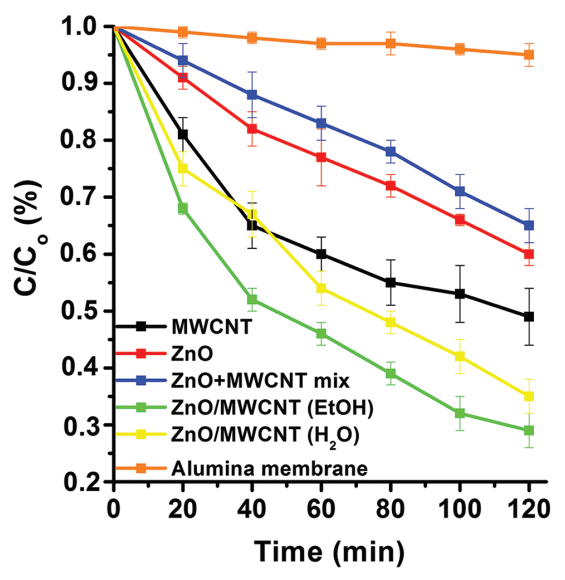

Figure 5. Photocatalytic decomposition of $\mathrm{AA}\left(\mathrm{c}_{\mathrm{AA}}=0.9 \mathrm{mM} ; \lambda_{\max }\right.$ at $365 \mathrm{~nm}$ ) by $\mathrm{ZnO}$ nanoparticles, MWCNT, pure alumina paper, the mechanic mixture of $\mathrm{ZnO}$ and MWCNT and $\mathrm{ZnO} / \mathrm{MWCNT}$ nanocomposites prepared in $\mathrm{EtOH}$ and $\mathrm{H}_{2} \mathrm{O}$.

Furthermore, $\mathrm{ZnO} / \mathrm{MWNT}$ s composite prepared in $\mathrm{EtOH}$ possesses the highest photocatalytic activity in the AA degradation reaction, which comes up to $71 \%$ in the AA photocatalysis processes. While by ZnO/MWCNT photocatalyst, 71\% (using EtOH as solvent-Fig. 5 green curve) and $65 \%$ (using $\mathrm{H}_{2} \mathrm{O}$ as solvent-Fig. 5 yellow curve) AA was decomposed after 120 minutes of irradiation, by ZnO-MWCNT mechanical mixture only $35 \%$ of AA was degraded after 120 minutes. Furthermore, it was found that the decomposition curve shape of pure MWCNT (Fig. 5 black curve) is different from other curves, which is related to the great adsorption of AA by MWNTs because of high specific surface area $\left(182.1 \mathrm{~m}^{2} / \mathrm{g}\right)$ and the tubular structure of MWNTs. ${ }^{17}$ Presumably, this can be a plausible explanation for higher photocatalytic activity of MWCNT compared to $\mathrm{ZnO}$ or the $\mathrm{ZnO}+\mathrm{MWCNT}$ mechanical mixture.

\section{CONCLUSION}

$\mathrm{ZnO}$ nanoparticles were successfully coated on the surface of SDS modified MWCNT by a noncovalent impregnation method. It can be concluded that synthesis were successful in every case but the structure of the ZnO/MWCNT composites were different. Applying TEM technique it was verified that different layer construction and morphology can be obtained using EtOH and $\mathrm{H}_{2} \mathrm{O}$ as solvents. Products of impregnation method were ideal candidates as starting material in photocatalytic measurements due to the partially covered MWCNTs which are involved the adsorption process during photocatalysis.

As-prepared ZnO/MWCNT nanocomposites exhibit enhanced photocatalytic degradation property of AA, which is probably cause by electron transfer processes from the attached $\mathrm{ZnO}$ to MWCNT. It is known, carbon nanotubes are relatively good electron acceptors, ${ }^{44}$ while semiconductor $\mathrm{ZnO}$ can be considered as good electron donor under UV illumination. ${ }^{9}$ Based on the earlier literature ${ }^{45}$ and the above results are presented in this study, the enhanced photocatalytic activity of $\mathrm{ZnO} / \mathrm{MWCNT}$ nanocomposite presumably originating from the electron transfer processes. MWCNT acts as a photogenerated electron acceptor to promote interfacial electron transfer processes from the attached $\mathrm{ZnO}$ to the carbon nanotube. Thus, the recombination of photoinduced electron and hole is retarded and the photocatalytic property of $\mathrm{ZnO}$ coated MWCNT composite is improved. ${ }^{9}$ Consequently, the enhanced photocatalytic activity of $\mathrm{ZnO} / \mathrm{MWCNT}$ nanocomposites denotes that good interfacial combination exists between $\mathrm{ZnO}$ nanoparticles and the surface modified MWCNT in the as-prepared ZnO/MWCNT composites.

The synthesized ZnO/MWCNT nanocomposite prepared in EtOH showed the highest photocatalytic efficiency (71\%) during the UV irradiated degradation of AA. The $\mathrm{ZnO} / \mathrm{MWCNT}$ composites with good photoactivity would be promising for practical use in pollutant decomposition as an effective photocatalyst.

Acknowledgments: Special thanks to Professor László Forró and his research group in École Polytechnique Fédérale de Lausanne (EPFL) to provide us the multiwalled carbon nanotubes. This work was supported by grants from Switzerland through Swiss Contribution $(\mathrm{SH} / 7 / 2 / 20)$. Zoltan Nemeth is very grateful for the financial support by the ÚNKP-17-4-I-ME/12. New National Excellence Program of the Ministry of Human Capacities. K. Hernadi acknowledges the financial support of GINOP2.3.2-15-2016-00013 project, too.

\section{References and Notes}

1. H. Chu, L. Wei, R. Cui, J. Wang, and Y. Li, Coord. Chem. Rev. 254, 1117 (2010).

2. P. M. Ajayan and O. Z. Zhou, Appl. Phys. 80, 391 (2001).

3. M. F. L. Volder, S. H. Tawfick, R. H. Baughman, and A. J. Hart, Science 339, 535 (2013).

4. C. W. Tan, K. H. Tan, Y. T. Ong, A. R. Mohamed, S. H. Zein, and S. H. Tan, Environ. Chem. Lett. 10, 265 (2012).

5. Y. Sakata, M. A. Uddin, A. Muto, and M. Imaoka, Micropor. Mater. 9, 183 (1997)

6. R. Das, S. B. A. Hamid, M. E. Ali, A. F. Ismail, M. S. M. Annuar, and S. Ramakrishna, Desalin. 354, 160 (2014).

7. T. A. Saleh and V. K. Gupta, Colloid. Interface Sci. 362, 337 (2011)

8. J. E. Riggs, Z. Guo, D. L. Carroll, and Y.-P. Sun, J. Am. Chem. Soc. 122, 5897 (2000).

9. V. Subramanian, E. E. Wolf, and P. V. Kamat, J. Am. Chem. Soc. 126, 4943 (2004).

10. Q. Geng, Q. Guo, C. Cao, and L. Wang, Ind. Eng. Chem. Res. 47, 2561 (2008).

11. B. Reti, K. Nemeth, Z. Nemeth, K. Mogyorosi, K. Marko, A. Erdohelyi, A. Dombi, and K. Hernadi, Phys. Stat. Sol. B 248, 2475 (2011).

12. A. Jitinau, T. Cacciaguerra, R. Benoit, S. Delpeux, F. Béguin, and S. Bonnamy, Carbon 42, 1147 (2004)

13. V. M. Aroutiounian, V. M. Arakelyan, E. A. Khachaturyan, G. E. Shahnararyan, M. S. Aleksanyan, L. Forro, A. Magrez, K. Hernadi, and Z. Nemeth, Sens. Act. B 173, 890 (2012). 
14. J. Khanderi, C. Contiu, J. Engstler, R. C. Hoffmann, J. J. Schneider, A. Drochner, and H. Vogel, Nanoscale 3, 1102 (2011).

15. Y. Yu, L. Ma, W. Huang, F. Du, J. C. Yu, J. Yu, J. Wang, and P. K. Wong, Carbon 43, 670 (2005).

16. L. P. Zhu, G. H. Liao, W. Y. Huang, L. L. Ma, Y. Yang, Y. Yu, and S. Y. Fu, Mat. Sci. Eng. B 163, 194 (2009).

17. L. Jiang and L. Gao, Mat. Chem. Phys. 91, 313 (2005).

18. X. Wang, B. Xia, X. Zhu, J. Chen, S. Qui, and J. Li, J. Sol. Stat. Chem. 181, 822 (2008).

19. M. H. Huang, S. Mao, H. Feick, H. Q. Yan, Y. Y. Wu, H. Kind, E. Weber, R. Russo, and P. D. Yang, Science 292, 1897 (2001).

20. Z. L. Jiang, Z. X. Xie, X. H. Zhang, S. C. Lin, T. Xu, S. Y. Xie, R. B. Huang, and L. S. Zheng, Adv. Mater. 16, 904 (2004).

21. D. Yin, L. Zhang, B. Liu, and M. Wu, J. Nanosci. Nanotechol. 12, 937 (2012).

22. S. A. Khayyat, M. Abaker, A. Umar, M. O. Alkattan, N. D. Alharbi, and S. Baskoutas, J. Nanosci. Nanotechnol. 12, 8453 (2012).

23. K. R. Lee, S. Park, K. W. Lee, and J. H. Lee, J. Mater. Sci. Lett. 22, 65 (2003).

24. J. W. Liu, X. J. Li, and L. M. Dai, Adv. Mater. 18, 1740 (2006).

25. Y. W. Zhu, H. I. Elim, Y. L. Foo, T. Yu, Y. J. Liu, W. Ji, J. Y. Lee, Z. X. Shen, A. T. S. Wee, J. T. L. Thong, and C. H. Sow, Adv. Mater. 18, 587 (2006).

26. M. Alaf, D. Gultekin, and H. Akbulut, Acta Phys. Pol. A 125, 426 (2014).

27. Y. W. Koh, M. Lin, C. K. Tan, Y. L. Foo, and K. P. Loh, J. Phys. Chem. B 108, 11419 (2004).

28. C. S. Chen, X. H. Chen, B. Yi, T. G. Liu, W. H. Li, L. S. Xu, Z. Yang, H. Zhang, and Y. G. Wang, Acta Mater. 54, 5401 (2006).
29. L. Fu, G. Lai, H. Zhang, and A. Yu, J. Nanosci. Nanotechnol. 15, 4325 (2015).

30. E. A. Whitsitt and A. R. Barron, Nano Lett. 3, 775 (2002).

31. A. Di Crescenzo, V. Ettorre, and A. Fontana, Beilstein J. Nanotechnol. 5, 1675 (2014).

32. L. Q. Jiang, L. Gao, and J. Sun, J. Colloid Interf. Sci. 260, 89 (2003).

33. P. Berki, Z. Nemeth, B. Reti, O. Berkesi, A. Magrez, V. Aroutiounian, L. Forro, and K. Hernadi, Carbon 60, 266 (2013).

34. Z. Nemeth, E. Horvath, A. Magrez, B. Reti, P. Berki, L. Forro, and K. Hernadi, Mat. Des. 86, 198 (2015).

35. E. Couteau, K. Hernadi, J. W. Seo, L. Thien-Nga, Cs. Miko, R. Gaal, and L. Forro, Chem. Phys. Lett. 378, 9 (2003).

36. A. Magrez, J. W. Seo, Cs. Miko, K. Hernadi, and L. Forro, J. Phys. Chem. B 109, 10087 (2005).

37. R. Smajda, M. Mionic, M. Duchamo, J. C. Anderson, and L. Forro, Phys. Stat. Sol. C 7, 1236 (2010).

38. S. Brunauer, P. H. Emett, and E. Teller, J. Am. Chem. Soc. 60, 309 (1938).

39. http://www.cotronics.com/vo/cotr/pdf/300.pdf.

40. C. L. Bianchi, S. Gatto, C. Pirola, A. Naldoni, A. Di Michele, G. Cerrato, V. Crocella, and V. Capucci, Appl. Catal. B: Environ. 146, 123 (2014).

41. B. S. Ong, L. Chensha, L. Yuning, Y. Wu, and R. Loutfy, J. Am. Chem. Soc. 129, 2750 (2007).

42. A. L. Patterson, Phys. Rev. 56978 (1939).

43. J. Yang, B. Wei, X. Li, J. Wang, H. Zhai, X. Li, Y. Sui, Y. Liu, J. Wang, J. Lang, and Q. Zhang, Crystal Res. Tech. 50, 840 (2015).

44. Y. Sun, S. R. Wilson, and D. I. Schuster, J. Am. Chem. Soc. 123, 5348 (2001)

45. J. Sun, L. Gao, and M. Iwasa, Chem. Commun. 7, 832 (2004).

Received: 26 September 2017. Accepted: 20 February 2018. 